\title{
Amyloid pathology and synaptic loss in pathological aging
}

\author{
Eleni Gkanatsiou $^{1,2}$ (1) | Johanna Nilsson ${ }^{1,2}$ | Christina E. Toomey ${ }^{3,4,5}$ | Agathe Vrillon ${ }^{6}$ | \\ Hlin Kvartsberg $^{1,2}$ | Erik Portelius ${ }^{1,2}$ | Henrik Zetterberg ${ }^{1,2,4,5,7}$ | Kaj Blennow ${ }^{1,2}$ | \\ Ann Brinkmalm $^{1,2}$ | Tammaryn Lashley ${ }^{3,5}$ | Gunnar Brinkmalm ${ }^{1,2}$
}

${ }^{1}$ Department of Psychiatry and Neurochemistry, Institute of Neuroscience and Physiology, the Sahlgrenska Academy at the University of Gothenburg, Mölndal, Sweden

${ }^{2}$ Clinical Neurochemistry Laboratory, Sahlgrenska University Hospital, Mölndal, Sweden

${ }^{3}$ The Queen Square Brain Bank for Neurological Disorders, Department of Clinical and Movement Neurosciences, UCL Institute of Neurology, London, UK

${ }^{4}$ UK Dementia Research Institute at UCL, London, UK

${ }^{5}$ Department of Neurodegenerative Disease, UCL Institute of Neurology, Queen Square, London, UK

${ }^{6}$ Center of Cognitive Neurology, Lariboisière Fernand-Widal Hospital, APHP, University of Paris Diderot, Paris, France

${ }^{7}$ Hong Kong Center for Neurodegenerative Diseases, Hong Kong, China

\section{Correspondence}

Eleni Gkanatsiou, Department of Psychiatry and Neurochemistry, Institute of Neuroscience and Physiology, the Sahlgrenska Academy at the University of Gothenburg, S-431 80 Mölndal, Sweden. Email: eleni.gkanatsiou@gu.se

\section{Funding information}

H2020 European Research Council;

Alzheimerfonden; Knut och Alice

Wallenbergs Stiftelse; Torsten

Söderbergs Stiftelse; Demensförbundet;

Vetenskapsrådet

\begin{abstract}
Alzheimer's disease (AD) is a neurodegenerative disease characterized by progressive memory dysfunction and cognitive decline. Pathological aging (PA) describes patients who are amyloid-positive but cognitively unimpaired at time of death. Both $A D$ and PA contain amyloid plaques dominated by amyloid $\beta(A \beta)$ peptides. In this study, we investigated and compared synaptic protein levels, amyloid plaque load, and $A \beta$ peptide patterns between $A D$ and PA. Two cohorts of post-mortem brain tissue were investigated. In the first, consisting of controls, PA, AD, and familial AD (FAD) individuals, synaptic proteins extracted with tris(hydroxymethyl)aminomethane-buffered saline (TBS) were analyzed. In the second, consisting of tissue from AD and PA patients from three different regions (occipital lobe, frontal lobe, and cerebellum), a two-step extraction was performed. Five synaptic proteins were extracted using TBS, and from the remaining portion $A \beta$ peptides were extracted using formic acid. Subsequently, immunoprecipitation with several antibodies targeting different proteins/peptides was performed for both fractions, which were subsequently analyzed by mass spectrometry. The levels of synaptic proteins were lower in $A D$ (and FAD) compared with PA (and controls), confirming synaptic loss in AD patients. The amyloid plaque load was increased in $A D$ compared with $P A$, and the relative amount of $A \beta 40$ was higher in $A D$ while for $A \beta 42$ it was higher in PA. In $A D$ loss of synaptic function was associated with increased plaque load and increased amounts of $A \beta 40$ compared with PA cases, suggesting that synaptic function is preserved in PA cases even in the presence of $A \beta$.
\end{abstract}

\section{KEYWORDS}

Alzheimer's disease, amyloid beta, immunoprecipitation, mass spectrometry, pathological aging, RBM3, SNAP-25, synaptophysin, synaptotagmin-1, synaptotagmin-7

Abbreviations: AD, Alzheimer's disease; A , amyloid beta; CAA, cerebral amyloid angiopathy; CU-AP, cognitively unimpaired with amyloid pathology; DAB, 3,3'-di-aminobenzidine; ESI, electrospray ionization; FA, formic acid; FAD, familial AD; IP, immunoprecipitation; LC, liquid chromatography; MALDI, Matrix-assisted laser desorption/ionization; MS, mass spectrometry; PA, pathological aging; PET, positron emission tomography; RBM3, cold-shock RNA-binding protein 3; SNAP-25, synaptosomal-associated protein 25; TBS, tris(hydroxymethyl)aminomethanebuffered saline; Tris, tris(hydroxymethyl)aminomethane.

Eleni Gkanatsiou and Johanna Nilsson contributed equally.

This article is part of the special issue "Mass Spectrometry in Alzheimer Disease".

This is an open access article under the terms of the Creative Commons Attribution-NonCommercial License, which permits use, distribution and reproduction in any medium, provided the original work is properly cited and is not used for commercial purposes.

(c) 2021 The Authors. Journal of Neurochemistry published by John Wiley \& Sons Ltd on behalf of International Society for Neurochemistry. 


\section{1 | INTRODUCTION}

Alzheimer's disease (AD) is a neurodegenerative disease characterized by progressive memory dysfunction and cognitive decline. It is the most common cause of dementia and as of 2018, 50 million people were estimated to live with AD (Patterson, 2018). Pathological hallmarks of $A D$ include the presence of amyloid plaques and neurofibrillary tangles, consisting of abnormally aggregated amyloid $\beta(A \beta)$ peptides and tau protein, respectively. Another prominent feature of $A D$ is early synaptic pathology, which also correlates with cognitive decline (Terry et al., 1991). However, there are patients without cognitive impairment that also display the pathological hallmarks of $A D$. Yet, based on the current neuropathological staging, they typically do not reach the amyloid plaque load required to qualify pathologically as AD (Montine et al., 2012; Thal et al., 2002). This is known as either pathological aging (PA) or cognitively unimpaired with amyloid pathology (CU-AP) (Kvartsberg et al., 2019). The finding has sparked a debate on whether this might be due to protective factors preventing deleterious effects on neuronal function by the amyloid pathology, or if they are simply cases of preclinical AD.

Due to the slowly progressing nature of $A D$, the pathologies appear at least 20 years before clinical manifestations (Jack et al. 2013a). Initially, A $\beta$ accumulates in the brain in the form of plaques, followed by tangle formation and synaptic loss and, finally, mainly amnestic symptoms arise (Jack et al., 2013b). In AD brains, the synapse loss has been estimated to exceed $40 \%$ in certain brain regions (DeKosky et al., 2002). Moreover, the synapses are dysfunctional before they visibly degenerate, both in the form of abnormal morphology and alterations in the synaptic vesicle machinery (Overk \& Masliah, 2014). To quantify synapse loss in living patients, biomarkers reflecting the synaptic pathology are needed and we have previously shown that synaptotagmin-1 and synaptosomal-associated protein 25 (SNAP-25) are two emerging presynaptic biomarkers (Brinkmalm, Brinkmalm, Honer, Frölich, et al., 2014; Clarke et al., 2019; Galasko et al., 2019; Tible et al., 2020). Synaptotagmin-1 is a vital protein for neurotransmitter release in hippocampal neurons due to its function as a calcium-sensor vesicle protein (Courtney et al., 2019). SNAP-25, on the other hand, is a t-SNARE protein that exists as two alternatively spliced isoforms: SNAP-25A and SNAP25B (Irfan et al., 2019). SNAP-25 is responsible for docking and fusion to the plasma membrane during vesicular exocytosis, a process which in turn synaptotagmin-1 controls and triggers via its $\mathrm{Ca}^{2+}$ sensitivity (Mohrmann et al., 2013; Südhof, 2004). Both proteins have been repeatedly shown in several studies to have increased levels in AD compared with controls in the cerebrospinal fluid (CSF) (Brinkmalm, Brinkmalm, Honer, Frölich, et al., 2014; Clarke et al., 2019; Galasko et al., 2019; Ohrfelt et al., 2016; Tible et al., 2020) and decreased levels in post-mortem brain tissue (Brinkmalm et al., 2014c; Reddy et al., 2005). Other members of the synaptotagmin family such as synaptotagmin-7 have also been indicated as potential biomarkers of AD (Barthet et al., 2018). Synaptotagmin-7 has a similar function as synaptotagmin-1, but differs in the location, i.e., synaptic plasma membrane instead of synaptic vesicles, and in $\mathrm{Ca}^{2+}$ affinity (5-20 fold higher) (Sugita et al., 2002). Additionally, a potential biomarker candidate for synaptic loss is synaptophysin, which is the most commonly used synaptic immunohistochemistry marker. The reason for its popularity in immunostaining is that it is one of the most abundant integral synaptic vesicle and plasma proteins at the synapse. In post-mortem brain tissue, its level has been found to be reduced in AD (Davidsson \& Blennow, 1998; Sze et al., 1997), and studies indicate a more severe loss than for other synaptic proteins including synaptotagmin-1 (Reddy et al., 2005). Further, to quantify neurodegeneration, the cold-shock RNA-binding protein 3 (RBM3) has been indicated to be a good biomarker in AD. In a study by Peretti et al., it was found that synapse regeneration, which is impaired in neurodegenerative diseases such as AD, was associated with a failure to induce RBM3 (Peretti et al., 2015).

Recent research has indicated that the pathological role of $A \beta$ during disease progression is acted out at the neuronal synapse. $A \beta$ oligomers seem to not only accumulate at the synaptic site, but also to be transported and interfere with synaptic function by interaction with a number of presynaptic and postsynaptic receptors (Chen et al., 2019; Cline et al., 2018). Abnormal A $\beta$ accumulation has been shown to have a direct toxic effect on neurons and synapses, and plaque formation disturbs cell communication (Mucke \& Selkoe, 2012). The $A \beta$ deposition in the brain is not homogeneous and has a progressive spreading between brain regions. The first areas affected are the neocortical regions while the cerebellum is affected last; at this stage the disease is severe (Thal et al., 2002). More recently, longitudinal positron emission tomography (PET) studies of $A D$ patients have shown more detailed $A \beta$ progression (Mattsson et al., 2019). A $\beta$ peptides are produced by enzymatic processing of the transmembrane amyloid precursor protein (APP). Cleavage of APP by $\beta$ - and $\gamma$-secretase, in the so-called amyloidogenic APP processing pathway, generates $A \beta$ peptides of different lengths of which $A \beta$ peptides ending at amino acid $42(A \beta X-42)$ are most prone to aggregation (Yan \& Wang, 2006) It is hypothesized that in $A D$ an imbalance between production and clearance of $A \beta$ leads to the formation of oligomers and finally extracellular insoluble amyloid plaques (Hardy \& Higgins, 1992). Amyloid plaques can either be characterized as diffuse or dense-core plaques. Previous studies have shown that the two types differ in major constituents. In diffuse plaques, $\mathrm{A} \beta \mathrm{X}-42$ dominates over the whole plaque area (Iwatsubo et al., 1994a, 1995; Michno et al., 2019; Tamaoka et al., 1995). In dense-core plaques, on the other hand, $A \beta X-40$ dominates in the core, and $A \beta X-42$ dominates in the diffuse part surrounding the core (Iwatsubo et al., 1994b; Michno et al., 2019). Moreover, $\mathrm{A} \beta \mathrm{X}-40$ is also the major component in the vessel amyloidosis found in cerebral amyloid angiopathy (CAA), a pathology present in $80 \%$ of AD patients (Revesz et al., 2009).

Immunoprecipitation (IP) followed by mass spectrometry (MS) has been used in several studies to identify and characterize differentially expressed proteins in post-mortem brain tissue in relation to pathology. It is, for example, a suitable method to simultaneously quantify $A \beta$ load and to profile $A \beta$ peptide patterns (Portelius et al., 2007). It is also an established method to quantify SNAP-25 and 
synaptotagmin-1 as an estimate of synapse dysfunction and degeneration (Brinkmalm, Brinkmalm, Honer, Frölich, et al., 2014; Ohrfelt et al., 2016). In this study, we present three novel MS-based in-house developed assays for RBM3, synaptophysin, and a combination of synaptotagmin-7, synaptotagmin-1, and SNAP-25 as potential biomarkers of synaptic dysfunction and degeneration. In previous studies, we used different combinations of detergents and found that even though high amounts of synaptic proteins were detected in Triton X-100 and sodium dodecyl sulphate (SDS) fractions, the protein forms found in the TBS fraction were more likely to be representative of the forms found in CSF (Brinkmalm, Brinkmalm, Honer, Frölich, et al., 2014; Brinkmalm et al., 2014b; Ohrfelt et al., 2016). Since clinically relevant biomarkers of synaptic loss or dysfunction are most likely to be found in biofluids such as cerebrospinal fluid or blood we have focused this study on synaptic proteins in the TBS fraction.

We aimed to investigate differences in potential synaptic degeneration between $A D$ and PA by quantifying the five synapseassociated proteins in a post-mortem brain tissue cohort, consisting of PA, AD, familial AD (FAD), and controls. Confirmation of the results was then performed in a different cohort consisting of $A D$ and $\mathrm{PA}$, expanded to three brain regions. In the same well characterized samples, an in-depth $A \beta$ investigation was performed in order to identify amyloid differences in patients with and without cognitive impairment, and finally to correlate the $A \beta$ load and peptide pattern with the synaptic dysfunction.

\section{2 | MATERIALS AND METHODS}

\section{1 | Patient characteristics}

Human post-mortem brain tissue from the frontal lobe, occipital lobe, and cerebellum was obtained from Queen Square Brain Bank for Neurological Disorders (QSBB), Department of Clinical and Movement Neurosciences, Institute of Neurology, University College London (UCL). In the exploratory cohort included occipital lobe of individuals with PA $(n=8), \operatorname{AD}(n=8), \operatorname{FAD}(n=8)$, and controls $(n=8)$. The validation cohort included three brain regions from PA $(n=16)$ and $\operatorname{AD}(n=16)$ patients. Samples were not blinded to the researchers. A block randomization was performed for sample preparation, and an additional simple randomization was performed prior to MS analyses. No sample size calculation was performed. The NINCDS (McKhann et al., 1984) criteria for probable AD in combination with the 2012 NIA-AA guidelines (Hyman et al., 2012) for neuropathological assessment of $A D$ were used. Thal phases ( $A \beta$ pathology) and Braak stages (tau pathology) were determined as described (Braak \& Braak, 1991; Thal et al., 2002). Other neuropathological scoring systems, including CERAD, ABC, and CAA were used as described previously (Montine et al., 2012; Rossetti et al., 2010; Skrobot et al., 2016). The FAD patients included in the study had mutations in either PSEN1 $(n=6)$ or APP $(n=2)$. PA and control cases were confirmed to be cognitively normal throughout life, and their causes of death were determined to be unrelated to any neurological disease. Further, at the pathological evaluation the PA patients were found to have $A \beta$ and tau pathologies; however, not severe enough to be classified as AD. The demographics and neuropathological classifications for both cohorts are given in Table 1, Tables S1 and S2. The study followed the Helsinki declaration and was approved by the regional ethics committees at UCL and the University of Gothenburg (Dnr: 012-15), but not pre-registered and all patients (or their relatives) had given their informed consent. The study was explorative, and no exclusion criteria were pre-determined.

\section{2 | Immunohistochemistry}

For immunohistochemistry analysis, $8-\mu m$-thick sections were cut from formalin-fixed, paraffin-embedded tissue from frontal cortex, occipital cortex, and cerebellum. Slides were dried overnight at $37^{\circ} \mathrm{C}$ before being adhered at $60^{\circ} \mathrm{C}$. The paraffin was removed using $x y-$ lene and slides were rehydrated with $100 \%$ ethanol. Endogenous peroxide activity was blocked using a methanol $/ \mathrm{H}_{2} \mathrm{O}_{2}(0.3 \%)$ solution (v/v). Sections were pre-treated with $98 \%$ formic acid (FA) $(\mathrm{v} / \mathrm{v})$ for $10 \mathrm{~min}$ at room temperature $21^{\circ} \mathrm{C}$ before being washed in $\mathrm{H}_{2} \mathrm{O}$. They were then placed in citrate buffer $(0.45 \mathrm{~g}$ citric acid, $5.8 \mathrm{~g}$ tri-sodium citrate, $2 \mathrm{~L}$ deionised $\mathrm{H}_{2} \mathrm{O}, \mathrm{pH}$ 6) and heated in a pressure cooker for $10 \mathrm{~min}$. Slides were incubated in $10 \%$ non-fat milk solution/TBS for $30 \mathrm{~min}$ at room temperature $21^{\circ} \mathrm{C}$, to block unspecific antibody binding. Primary antibody (A $\beta$, Dako M0872) was applied for $1 \mathrm{~h}$ at room temperature $21^{\circ} \mathrm{C}$ at a dilution of 1:100. The slides were washed in TBS-Tween-20 solution (Thermo Fisher Scientific) before being placed in the respective biotinylated secondary antibody (rabbit anti-mouse, 1:200) for $30 \mathrm{~min}$. After a second round of washing in TBS-Tween, Avidin-Biotin Complex solution (Vector) was applied for $30 \mathrm{~min}$. Slides were washed before 3,3'-di-aminobenzidine-TBS- $\mathrm{H}_{2} \mathrm{O}_{2}$ solution (1 $\mathrm{ml} 5 \% \mathrm{DAB}(\mathrm{w} / \mathrm{v})$ in $100 \mathrm{ml}$ TBS-Tween, $32 \mu \mathrm{l} \mathrm{H}_{2} \mathrm{O}_{2}$ ) was used as the chromogen, and slides were counterstained in Mayer's hematoxylin (1 g hematoxylin,

TABLE 1 Cohort demographics

\begin{tabular}{llll|} 
Cohort & Group & $\mathrm{n}(\mathrm{F} / \mathrm{M})$ & $\begin{array}{l}\text { Age of death, median } \\
\text { (interquartile interval) }\end{array}$ \\
\hline Explorative & $C O^{1}$ & $9(5 / 4)$ & $82(70-85)$ \\
& $P A^{2}$ & $9(7 / 2)$ & $88(86-93)$ \\
& $A D^{3}$ & $8(3 / 5)$ & $73.5(65-81)^{\mathrm{a}}$ \\
& $F A D^{4}$ & $8(5 / 3)$ & $53.95(48-64)^{\mathrm{b}, \mathrm{c}}$ \\
Validation & $P A$ & $16(10 / 6)$ & $88(83-92)$ \\
& $A D$ & $16(6 / 10)$ & $73.5(67-79)^{\mathrm{d}}$ \\
\hline
\end{tabular}

${ }^{1}$ Controls; ${ }^{2}$ Pathological aging; ${ }^{3}$ Alzheimer's disease; ${ }^{4}$ Familial AD. ${ }^{a}$ Kruskal-Wallis test with Dunn post hoc, $p<0.05$ compared with PA. ${ }^{b}$ Kruskal-Wallis test with Dunn post hoc, $p<0.05$ compared with controls.

${ }^{c}$ Kruskal-Wallis test with Dunn post hoc, $p<0.0001$ compared with PA. ${ }^{d}$ two-sided Mann-Whitney test, $p<0.001$ compared with PA. 
$50 \mathrm{~g}$ potassium, or aluminium alum, $0.2 \mathrm{~g}$ sodium iodate, $50 \mathrm{~g}$ chloral hydrate). Slides were dehydrated through $70 \%$ ethanol (v/v), 90\% ethanol ( $\mathrm{v} / \mathrm{v}), 100 \%$ ethanol $(\mathrm{v} / \mathrm{v})$ and xylene, then mounted using DPX mounting medium (Thermo Fisher Scientific).

\section{3 | Image analysis}

All sections were scanned using an Olympus VS120 scanner at 420x magnification, and a digital TIF image was then stored. QuPath (v2.0) was used to view the images, and images were analyzed in ImageJ (Bankhead et al., 2017). The extracted images were loaded into ImageJ (https://imagej.nih.gov/ij/) and the grey matter selected manually using the inbuilt polygon tool. A macro script was then used to determine the percentage of the area enclosed in the polygon that was stained with DAB using a threshold that had been determined with a set of images prior to the study. The threshold was determined manually by examining a range of images stained with the same antibody and adjusting the hue and saturation level. Once determined, the most suitable threshold was kept the same throughout. The macro created a black and white image in the process of calculating the area that had been stained.

\section{4 | Tissue preparation}

Fresh frozen cerebral tissue (90-110 mg pieces, consisting of both grey and white matter) was homogenized in $600 \mu$ tris(hydroxymethyl) aminomethane (Tris)-buffered saline (TBS), $\mathrm{pH} 7.6$, containing cOmplete (cat: 04693116001, Roche) protease inhibitor, using one $5 \mathrm{~mm}$ bead per sample in a TissueLyser (Qiagen) for 4 min at $30 \mathrm{~Hz}$. To the the homogenate $(700 \mu \mathrm{l}), 400 \mu \mathrm{l}$ TBS with inhibitor was further added and transferred to a new tube, and centrifuged at $31,000 \mathrm{~g}$ for $1 \mathrm{~h}$ at $+4^{\circ} \mathrm{C}$. The supernatant (TBS fraction) was transferred to a new tube and stored at $-80^{\circ} \mathrm{C}$ until further use. The pellet was resuspended in $1 \mathrm{ml}$ of $70 \% \mathrm{FA}(\mathrm{v} / \mathrm{v})$, followed by further homogenization in the Tissuelyser for $2 \mathrm{~min}$ at $30 \mathrm{~Hz}$ and subsequent sonication for $30 \mathrm{~s}$. The homogenate was centrifuged again at 31,000 $\mathrm{g}$ for $1 \mathrm{~h}$ at $+4^{\circ} \mathrm{C}$ and the supernatant (FA fraction) was dried down in a vacuum centrifuge.

\section{5 | Immunoprecipitation}

\subsection{1 | Amyloid $\beta$}

Prior to IP, the dried FA fractions were reconstituted in $200 \mu \mathrm{l} 70 \%$ FA (v/v), shaken for $30 \mathrm{~min}$ at room temperature $21^{\circ} \mathrm{C}$, and centrifuged at $31,000 \mathrm{~g}$ for $1 \mathrm{~h}$ at $+4^{\circ} \mathrm{C}$. The supernatant was removed and neutralized with $4 \mathrm{ml} 0.5 \mathrm{M}$ Tris. IP was performed as previously described with some modifications (Gkanatsiou et al., 2019). Briefly, the neutralized FA fraction was incubated overnight at $+4^{\circ} \mathrm{C}$ in $0.2 \%$ Triton X-100 in PBS (v/v) with a total of $50 \mu \mathrm{l}$ lgG-coated magnetic beads (Dynabeads M-280 Sheep anti-mouse, cat: 11202D, Thermo Fisher Scientific) that had previously been linked with $4 \mu \mathrm{g}$ each of mouse monoclonal 6E10 and 4G8 (cat: 803003 and 800711, Biolegend) per sample. By using an automated magnetic-particle KingFisher $\mathrm{ml}$ system (Thermo Fisher Scientific), the samples were then washed with PBS Triton X-100, PBS, and $50 \mathrm{mM}$ ammonium bicarbonate separately before elution in $100 \mu \mathrm{l} 0.5 \% \mathrm{FA}$. Eluates were dried down in a vacuum centrifuge and stored at $-80^{\circ} \mathrm{C}$ pending $\mathrm{MS}$ analysis. As a negative control experiment, the anti-A $\beta$ antibodies were substituted with anti-neurogranin antibodies.

\subsection{2 $\quad$ RBM3}

For IP of RBM3, the TBS fraction was incubated overnight at $+4^{\circ} \mathrm{C}$ in $0.2 \%$ Triton $\mathrm{X}-100(\mathrm{v} / \mathrm{v})$ in PBS with $100 \mu \mathrm{l}$ of IgG-coated magnetic beads (Dynabeads M-280 Sheep anti-rabbit, cat: 11203D, Thermo Fisher Scientific) that had been previously crosslinked with $0.5 \mu \mathrm{g}$ per sample RBM3 rabbit polyclonal antibody (cat: 14383-1-AP, Nordic Biosite). To remove impurities, the antibody crosslinked beads had previously been washed for $5 \mathrm{~min}$ in glycine $\mathrm{pH}$ 2. Using the KingFisher $\mathrm{ml}$ system, the samples were then washed with PBS Triton X-100, PBS, and $50 \mathrm{mM}$ ammonium bicarbonate separately before elution in $100 \mu \mathrm{l} 0.5 \%$ FA. As a negative control, the RBM3 antibody was substituted with the anti-synaptophysin antibody.

\subsection{3 | Synaptophysin, synaptotagmin-7, synaptotagmin-1, and SNAP-25}

For synaptotagmin-7, synaptophysin, synaptotagmin-1, and SNAP25 , the same protocol was used for IP by using the KingFisher Flex System (Thermo Fisher Scientific), an automated magnetic-particle processing system in 96-well format. The TBS fraction was diluted to $1 \mathrm{ml}$ in $0.05 \%$ PBS-Tween 20 and incubated at room temperature $21^{\circ} \mathrm{C}$ for $90 \mathrm{~min}$ with antibodies added to corresponding IgG-coated magnetic beads (Dynabeads M-280 Sheep anti-Mouse or anti-Rabbit IgG, Thermo Fisher Scientific). The following antibodies were used separately; synaptotagmin-7 (1 $\mu$ g per sample; cat: sc-293343, Santa Cruz Biotechnology), synaptophysin (0.15 $\mu \mathrm{g}$ per sample; cat: LSC346111, Nordic BioSite), SNAP-25 (0.5 $\mu$ g per sample; cat: SMI81, Nordic BioSite), and synaptotagmin-1 (0.5 $\mu$ g per sample; clone 41.1, Synaptic Systems). The samples were then sequentially washed with $0.05 \%$ PBS-Tween 20, PBS, and $50 \mathrm{mM}$ ammonium bicarbonate before elution in $150 \mu \mathrm{L} 0.5 \% \mathrm{FA}(\mathrm{v} / \mathrm{v})$.

All IP sample eluates except $A \beta$ were dried in a vacuum centrifuge and stored at $-20^{\circ} \mathrm{C}$ pending proteolytic digestion. The samples were digested with trypsin $(0.025 \mu \mathrm{g}$ per sample; Promega Co) overnight at $+37^{\circ} \mathrm{C}$. Five microliter $10 \% \mathrm{FA}(\mathrm{v} / \mathrm{v})$ was added to each sample to stop the digestion before again drying the samples in a vacuum centrifuge with subsequent storage at $-20^{\circ} \mathrm{C}$ pending MS analysis. 
The IP method for SNAP-25 and synaptotagmin-1 was optimized between the analysis of the explorative and validation cohorts. Changes made were: $0.005 \%$ PBS-Tween $20(\mathrm{v} / \mathrm{v})$ was used for incubation and washing and for digestion trypsin/LysC (0.3875 $\mu \mathrm{g}$ per sample; Promega Co) was used. For negative controls for each protein the corresponding antibody was substituted with another antibody, for SNAP-25 the anti-SYT1 antibody, for SYP the anti-RBM3 antibody, for SYT7 the anti-SYT1 antibody, and for SYT1 the antiSYT7 antibody was used.

\section{6 | Mass spectrometry}

\subsection{1 | Amyloid $\beta$}

Prior to MS analysis, samples were reconstituted in $5 \mu \mathrm{l} 0.1 \%$ $\mathrm{FA} / 20 \%$ acetonitrile in water ( $\mathrm{v} / \mathrm{v} / \mathrm{v})$. Analysis was performed using a Bruker Daltonics UltraFleXtreme matrix-assisted-laser-desorption/ ionization-time-of-flight/time-of-flight (MALDI-TOF/TOF) instrument. MALDI samples were prepared using the seed layer method as previously described (Gkanatsiou et al., 2019). An average of 10,000 shots was acquired for each spectrum (2,000 at a time using a random walk mode).

The $3 \mu$ left from MALDI preparation was dried and reconstituted in $7 \mu \mathrm{l} 8 \% \mathrm{FA} / 8 \%$ acetonitrile in water $(\mathrm{v} / \mathrm{v} / \mathrm{v})$, for analysis by nanoflow liquid chromatography (LC) coupled to electrospray ionization (ESI) hybrid quadrupole-orbitrap tandem MS (Dionex Ultimate 3000 system and Q Exactive, both Thermo Fisher Scientific) in a similar way as described previously (Brinkmalm et al., 2012; Gkanatsiou et al., 2019).

\subsection{2 | Parallel reaction monitoring analysis of synaptophysin, synaptotagmin-7, synaptotagmin-1, SNAP-25, and RBM3}

For the exploratory study, three parallel reaction monitoring (PRM) methods were used for quantitation, one measuring synaptotagmin1, synaptotagmin-7, and SNAP-25 simultaneously, and one each for RBM3 and for synaptophysin. One to three proteotypic peptides per protein to be targeted in the PRM analysis were selected based on results from explorative proteomics (data not shown). Heavy stable-isotope labeled peptides were ordered from Thermo Fisher Scientific (AQUA QuantProHeavy and HeavyPeptide FasTrack (RBM3)) and stored at $-20^{\circ} \mathrm{C}$. Before use, standards were mixed and diluted in $0.1 \% \mathrm{FA} / 5 \%$ acetonitrile in water $(\mathrm{v} / \mathrm{v} / \mathrm{v})$ to a concentration matching the native proteins. PRM analysis was performed using microflow LC (Ultimate 3000) coupled to ESI-hybrid quadrupoleorbitrap MS (Q Exactive). The separation was performed on a Hypersil Gold reversed-phase column (dim. $100 \times 2.1 \mathrm{~mm}$, particle size $1.9 \mu \mathrm{m}$, Thermo Fisher Scientific) using a flow-rate of $0.3 \mathrm{ml} / \mathrm{min}$, sample injection volume of $60 \mu \mathrm{l}$, and optimized gradients for $5 \mathrm{~min}$ (synaptotagmin-1, synaptotagmin-7, and SNAP-25), 8 min (RBM3) and $13 \mathrm{~min}$ (synaptophysin). Mobile phase A consisted of $0.1 \%$ FA in water ( $\mathrm{v} / \mathrm{v})$ and $\mathrm{B}$ was $84 \%$ acetonitrile/0.1\% FA in water $(\mathrm{v} / \mathrm{v} / \mathrm{v})$.

\subsection{3 | Selected reaction monitoring analysis of synaptotagmin-1 and SNAP-25}

For the validation study, an optimized high throughput selected reaction monitoring (SRM) method was used for the quantitation of synaptotagmin-1 and SNAP-25. Briefly, IP'd SNAP-25/synaptotagmin-1 together with isotopically labeled peptide standards (AQUA QuantProHeavy; Thermo Fisher Scientific) were digested directly in 96-well plates with trypsin/Lys-C and analyzed with microflow LC coupled to ESI-triple quadrupole MS (Agilent Technologies 1290 liquid chromatograph and 6495 mass spectrometer). The samples $(40 \mu \mathrm{l})$ were loaded directly onto a Hypersil Gold reversed-phase column (dim. $100 \times 2.1 \mathrm{~mm}$, particle size $1.9 \mu \mathrm{m}$ ) using a flow-rate of $0.3 \mathrm{ml} / \mathrm{min}$, separated with an optimized $10 \mathrm{~min}$ gradient. Mobile phase $A$ consisted of $0.1 \%$ FA in water $(\mathrm{v} / \mathrm{v})$ and $\mathrm{B}$ was $84 \%$ acetonitrile/0.1\% FA in water ( $\mathrm{v} / \mathrm{v} / \mathrm{v})$.

\subsubsection{Data processing and statistical analysis}

MALDI data were analyzed by using an in-house script to match the peak masses against the APP sequence. In some of the samples, the isotopic envelope of $A \beta 1-40$ and $A \beta 3-42$ was overlapping, so manual peak picking was performed instead of Bruker's SNAP function. MALDI does not generally give a linear response to the abundance of analyte in the sample spot when the analyte abundance variation is relatively large (here analyte is not confined to $A \beta$-species, but to the whole sample, including proteins non-specifically co-precipitated) (Medina et al., 1994; Westman et al., 1994). There is also a general risk that some analyte species can quench others. Under controlled conditions we have previously found that $A \beta$ peptides do not affect other $A \beta$ peptides noticeably, so the relative $A \beta$ peptide signal within a sample is reproducible. However, the signal between samples has generally been less reliable with the approach used here. Therefore, for each spectrum the individual $A \beta$ peak areas were normalized to the sum of all $A \beta$ peak areas in the same spectrum before further analysis; hence only a relative measurement of each $A \beta$ species was obtained. This gives an $A \beta$ pattern profile for each spectrum. Here it is important to note that by performing this normalization, the abundance of a particular peptide between samples, e.g., A $\beta 1-40$ or $A \beta 1-$ 42 , is no longer straightforward.

For the LC-MS acquisitions, database search (including isotope and charge deconvolution) was performed with PEAKS Studio v8.5 (Bioinformatics Solutions Inc.) against a custom-made APP database. For the synaptic biomarkers, Skyline 20.1 (MacCoss Lab Software) was used for data processing and to calculate peak areas; all peaks were inspected manually. Synaptic protein ratios were recalculated to concentrations using the standard concentrations added to each sample and then normalized against brain tissue mass. 
GraphPad Prism version 8 (GrahpPad Software, Inc.), was used for statistical analysis and plot generation. In the data set no outliers were found or removed; further the data were found to have a non-normal distribution, and thus non-parametric tests were used. For $A \beta$, the Mann-Whitney $U$-test was used to test the statistical significance for difference between the groups. For the synapseassociated proteins, statistical significance was tested with KruskalWallis for multiple comparisons followed by uncorrected Dunn's test (significance level 0.05). For the validation cohort, the test was only performed pairwise between PA and AD for each brain region. No adjustment was made for age, as age differences were considered inherent to the groups.

\section{3 | RESULTS}

\section{1 | Synaptic protein concentrations in the explorative study}

The first exploratory study consisted of brain tissue samples from the occipital cortex and contained four groups: controls, PA, AD, and FAD (Table S1). IP-MS experiments using other antibodies with CSF and TBS fraction of brain, which can serve as negative controls, have shown no unspecific binding of the synaptic proteins investigated here (data not shown). Generally, a trend of lower concentrations of synaptophysin, SNAP-25, synaptotagmin7 , and RBM3 was found in AD and FAD compared with controls and $P A$, indicating synapse protein loss in $A D$ and FAD but not in PA (Figure 1). PA tissue had significantly higher concentrations of RBM3, SNAP-25, and synaptotagmin-7 compared with FAD and RBM3 and SNAP-25 compared with AD. In addition, RBM3 concentration was significantly higher in controls than in $A D$ and $F A D$, where all three peptides showed similar results (Figure $\mathrm{S} 1$ ) and had a strong correlation. Synaptophysin and synaptotagmin-1 concentrations, however, did not differ significantly between any groups. Further, none of the proteins differed between controls and PA or between $A D$ and $F A D$, indicating no significant pathological synaptic protein loss in PA and a similar magnitude of loss in FAD and AD. As negative controls, pooled TBS fraction samples were analyzed by IP-MS using both antibodies directed at the protein of interest as well as a different antibody and in these cases no signals were observed (Figure S2).

\subsection{Synaptic protein concentrations in the validation PA/AD study}

The validation study (Figure 2 and Figure S3), focusing on AD and PA individuals, was extended to three brain regions (occipital lobe, frontal lobe, and cerebellum). In agreement with the results from the explorative cohort, several of the synaptic proteins had decreased concentrations in AD compared with PA. Both synaptophysin and RBM3 had decreased protein concentrations in both frontal and occipital lobes in $A D$ compared with PA. Synaptotagmin-1 only had significantly decreased concentrations for AD in comparison with PA in the occipital lobe and synaptotagmin-7 only in the frontal lobe. No protein concentration was significantly changed in the cerebellum. In the SRM-assay used in the validation study for SNAP-25 and synaptotagmin-1, we also monitored an isoform-specific form of SNAP-25 denoted "SNAP-25B" as well as the common N-terminal SNAP-25 peptide occurring in all SNAP-25 isoforms (Figure S4). Interestingly SNAP-25B was significantly decreased in both the frontal lobe and the occipital lobe, while N-terminal SNAP-25 was decreased in frontal lobe but not in the occipital lobe. This differs from the exploratory study where $\mathrm{N}$-terminal SNAP-25 concentrations were significantly decreased also in the occipital lobe.

In general, the strongest significant correlations were found between the concentration of SNAP-25B with RBM3 and synaptophysin (both $A D$ and PA in all three brain regions) (Figure S5). Synaptophysin concentrations also exhibited a significant, moderate to strong, positive correlation with synaptotagmin-7 (frontal lobe) and synaptotagmin-1 (occipital lobe). In the frontal lobe both the PA and $A D$ group exhibited moderate positive significant correlations between RBM3 and the N-terminal form of SNAP-25.

\subsection{A $\mathrm{A} \beta$ immunohistochemistry}

Immunohistochemistry staining of $A \beta$ plaques in the validation PA/AD study was performed to estimate the amount of $A \beta$ deposition in $A D$ and $P A$ individuals in the different brain regions. In representative immunohistochemical images of PA (Figure $3 a-c$ ) and $A D$ (Figure $3 d-f$ ) the difference in plaque load is observed. The semi-quantitative measurements of the area stained in the frontal, occipital, and cerebellum are shown in Figure $3 \mathrm{~g}$. Significantly higher $A \beta$ load was found in AD compared with PA in all regions.

\section{4 $\mathrm{A} \beta$ peptide patterns in $\mathrm{AD}$ and $\mathrm{PA}$}

The FA fraction of the samples in the validation study was utilized to compare the $A \beta$ peptide pattern for AD and PA, using MALDI-MS. As described in the method section, every individual spectrum is normalized using the sum of all detected $A \beta$ peptides; this leads to that abundancy cannot be straight-forwardly compared between samples. Hence, we introduce the concept relative fraction to distinguish from abundancy. Although the same $A \beta$ peptides were generally detected in both $A D$ and PA, their relative fractions differed (see Figure 4 for example spectra). $A \beta 1-40$ and $A \beta 4-40$ relative fractions were significantly higher in AD compared with PA in the occipital lobe, and the same tendency was observed in the frontal lobe (Figure 5). In the cerebellum, only $A \beta 4-40$ had this tendency. Contrary to this, the relative abundancies of $A \beta 1-42$ and $A \beta 4-42$ were generally higher in PA compared with $A D$, with significant differences in the frontal 

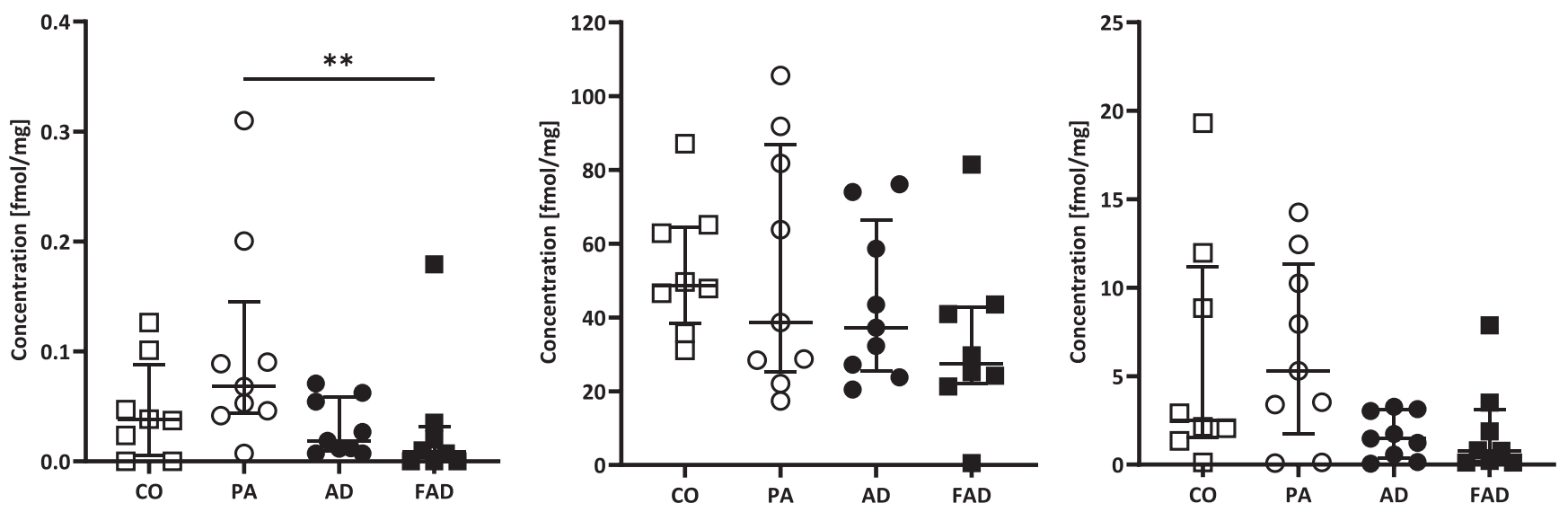

SNAP-25

RBM3
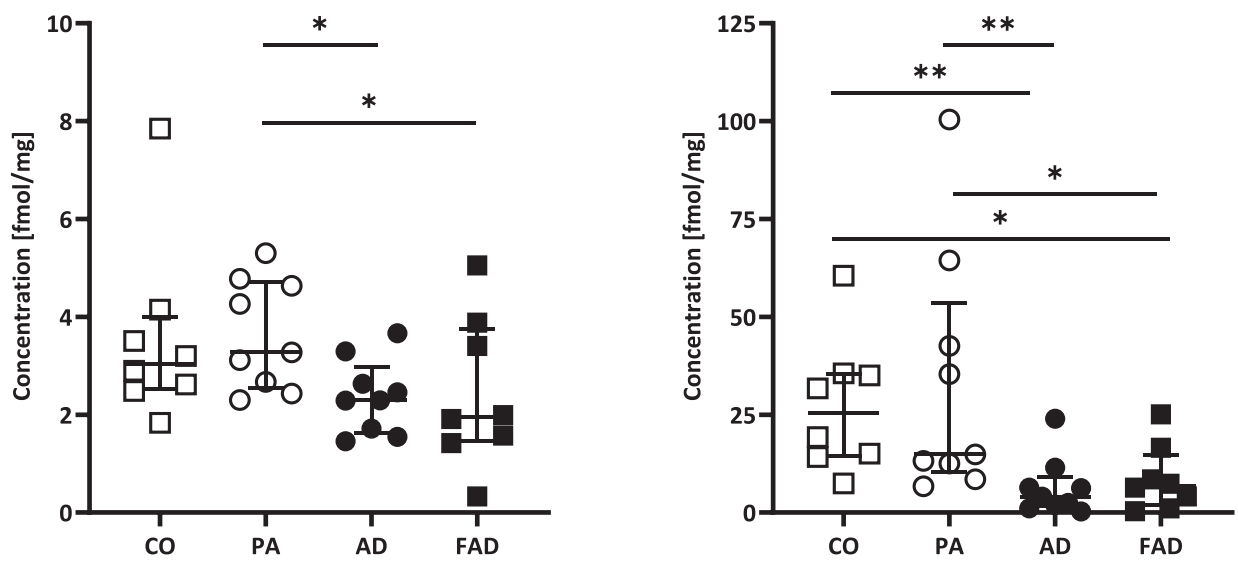

FIGURE 1 PRM analysis of synaptotagmin-7, synaptotagmin-1, synaptophysin, SNAP-25, and RBM3 (representative peptide) in the exploratory cohort consisting of PA $(n=8), \operatorname{AD}(n=8)$, FAD $(n=8)$, and controls $(C O, n=8)$ from occipital lobe. Statistical comparison with Kruskal-Wallis for multiple comparisons with uncorrected Dunn's test, $p$-value ${ }^{*} p \leq 0.05$ and ${ }^{* *} p \leq 0.01$. The bars indicate median with interquartile range. $n=$ number of patients

lobe for $A \beta 1-42$ and in the occipital lobe for $A \beta 4-42$. This should not be interpreted as $A \beta X-42$ abundancy is lower in $A D$ than in $P A$, which it is not. Both the immunohistochemistry data and the LC-ESI-MS data (not shown) indicate that the total $A \beta$ load, of which $A \beta X-42$ constitutes the bulk, is higher in $A D$ than PA. The relative fractions of pyroglutamate-modified peptides pGlu $A \beta 3-40$ and pGlu $A \beta 3$ 42 were both more prominent in $A D$ compared with PA in both the frontal and occipital lobes (significant increase for pGlu A $\beta 3-40$ in the occipital lobe). For the rest of the $A \beta$ peptides, a similar tendency was observed, with higher relative fractions of $A \beta X-40$ in $A D$ and $A \beta X-42$ in PA (Figure S6 and S7). Within the same patient group, there were no major $A \beta$ pattern differences between the frontal and the occipital lobe, but fewer peptides and lower total $A \beta$ load were observed in the cerebellum.

Analysis with nanoflow LC-ESI-MS/MS allowed a more in-depth identification of low-abundance $A \beta$ peptides that were not possible to detect with MALDI-MS. In total, 219 A $\beta$ peptides (including oxidized and pyroglutamate forms) were identified in the sample set (Table S6). In agreement with the MALDI-MS analysis, there was no difference between $A D$ and $P A$ in the identified $A \beta$ peptide species, but rather in the relative abundance pattern. As with the MALDI-MS analysis, the relative fractions of $A \beta X-40$, pGlu $A \beta 3-40$, and pGlu A 3 3-42 were generally higher in AD compared with PA, while the relative fractions of non-modified $A \beta X-42$ were higher in PA. Furthermore, the total $A \beta$ load was highest in the occipital lobe, followed by the frontal lobe and cerebellum.

In several individuals, $A \beta 1-37, A \beta 1-38$, and $A \beta 1-39$ species were clearly visible (Figures S6 and S8). The relative fractions of these peptides were most prominent in the $A D$ group and in the occipital lobe followed by the frontal lobe. These peptides were observed mainly in brains with CAA score $\geq 2$ (Table S2).

As a negative control, the FA fraction was analyzed by IP-MS using antibodies directed at a different protein (neurogranin); no $A \beta$ peptides were observed (Figure S9). 

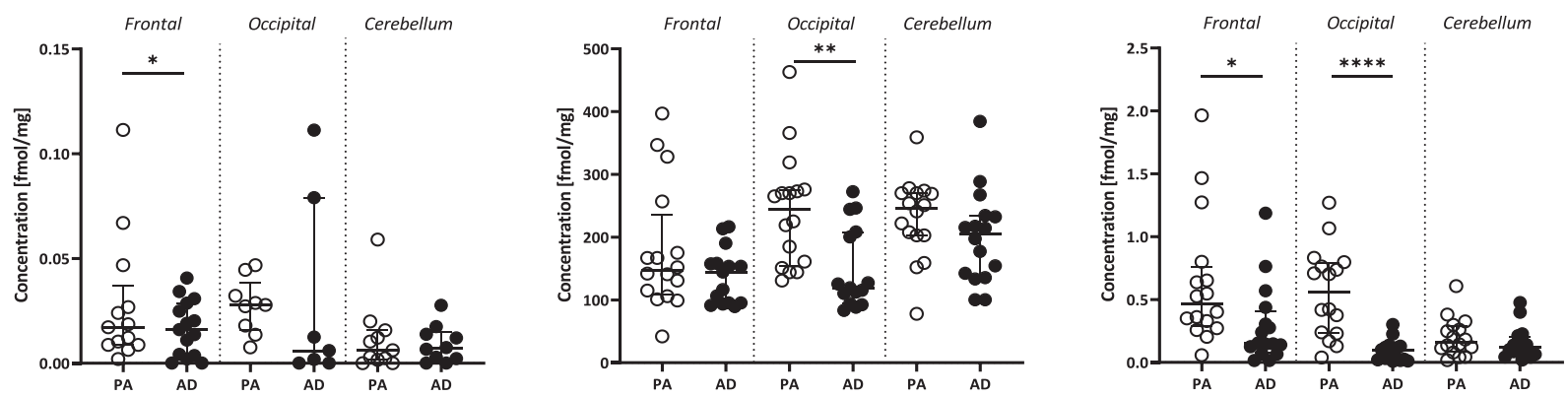

SNAP-25

SNAP-25B

RBM3
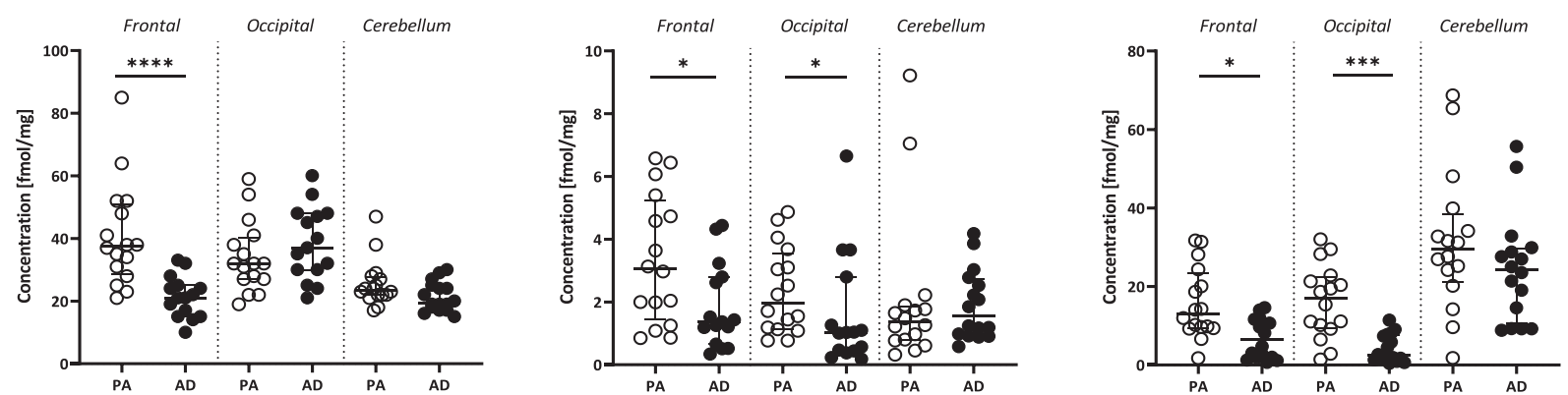

FIGURE 2 PRM/SRM analysis of synaptotagmin-7, synaptotagmin-1, synaptophysin, SNAP-25 (2 peptides), and RBM3 (representative peptide) in the validation cohort consisting of PA $(n=16)$ and $\operatorname{AD}(n=16)$ from three different brain regions (frontal, occipital, and cerebellum). Statistical comparison with pairwise Kruskal-Wallis for multiple comparisons with uncorrected Dunn's test, $p$-value ${ }^{*} p \leq 0.05$, ${ }^{* *} p \leq 0.01,{ }^{* * *} p \leq 0.001$ and ${ }^{* * * *} p \leq 0.0001$. The bars indicate median with interquartile range. $n=$ number of patients

\subsection{Correlations of synapse-associated proteins with $A \beta$ peptides}

In $\mathrm{AD}$ patients, all synapse-associated proteins exhibited a trend toward a weak to moderate positive correlation with the relative $A \beta X-42$ fractions and a negative correlation with relative $A \beta X-40$ fractions (except $A \beta 2-40$ ) in the frontal lobe (Figure S10). Synaptophysin, RBM3, and SNAP-25B also showed a similar trend in the occipital lobe. In PA patients, a significant strong and negative correlation was found between relative pGlu A $\beta 3-42$ fraction and all the synapse-associated proteins, except SNAP-25 in the occipital lobe. A similar but less pronounced trend was found for the same proteins in the frontal lobe.

\subsection{Correlations between $\mathrm{A} \beta$ peptides and CAA}

Strong correlations were observed between relative $A \beta 1-40, A \beta 4$ 40 , and $A \beta 5-40$ fractions in both frontal lobe and occipital lobe for $A D$ and $C A A$, and for PA the correlation was strong between relative $A \beta 1-40$ and $A \beta 4-40$ fractions in the same brain regions (Figure S10). The correlations between relative $A \beta 1-42, A \beta 2-42, A \beta 4-42$, and $A \beta 5-42$ fractions for $A D$ in the frontal and occipital lobes were similar, but less accentuated compared with the $A \beta X-40$ species. For
PA in the same brain regions the correlations between relative $A \beta X-$ 42 fractions were more disperse. The number of $A \beta$ peptides found in the cerebellum was much lower and no reliable correlation calculations were obtained. Further, in $A D$ patients there was a relatively strong negative correlation between relative $A \beta X-42$ and $A \beta X-40$ fractions as well as between relative $A \beta X-42$ and $A \beta 1-37,38,39$ fractions, particularly in the occipital lobe but also in the frontal (Figure $\mathrm{S} 10)$. A moderate to weak positive correlation between relative $A \beta 1$ 37,38,39 fractions and CAA score was observed for AD patients in the frontal lobe, but not in the other lobes and not for PA.

\section{DISCUSSION}

Synaptic pathology, which is an early indicator of $A D$, to our knowledge, has not been extensively studied in relation to pathological aging. The method used is based on that initially developed in our laboratory, where several consecutive extractions (Tris, $0.5 \%$ and $2 \%$ Triton X-100, and 0.5\% SDS) were performed (Brinkmalm et al., 2014b; Ohrfelt et al., 2011). Here we used modified in-house method variants (with TBS instead of Tris) to quantify the synaptic proteins, synaptotagmin-7, synaptophysin, SNAP-25, and synaptotagmin-1, together with RBM3, a cold-shock protein with a critical role in mediating synaptic repair processes, in a post-mortem brain cohort. Here 
FIGURE 3 Representative

immunohistochemistry images of stained

$A \beta$ plaques in frontal cortex brain tissue

for PA $(n=16)(a-c)$ and $A D(n=16)$

(d-f). (a) and (d) show full tissue sections

(scale bar $=2,000 \mu \mathrm{m}$ ). (b) and (e) show the pathology across all cortical layers (scale bar $=200 \mu \mathrm{m}$ ). (c) and (f) show the pathology at $4 \times$ magnification (scale bar $=200 \mu \mathrm{m})$. $(\mathrm{g})$ shows scatter plot of the $A \beta$ load in the frontal lobe, occipital lobe, and cerebellum. Mann-Whitney was used for statistical evaluation; $p$-value ${ }^{* * *} p \leq 0.001$ and ${ }^{* * * *} p \leq 0.0001$. The bars indicate median with interquartile range. $n=$ number of patients
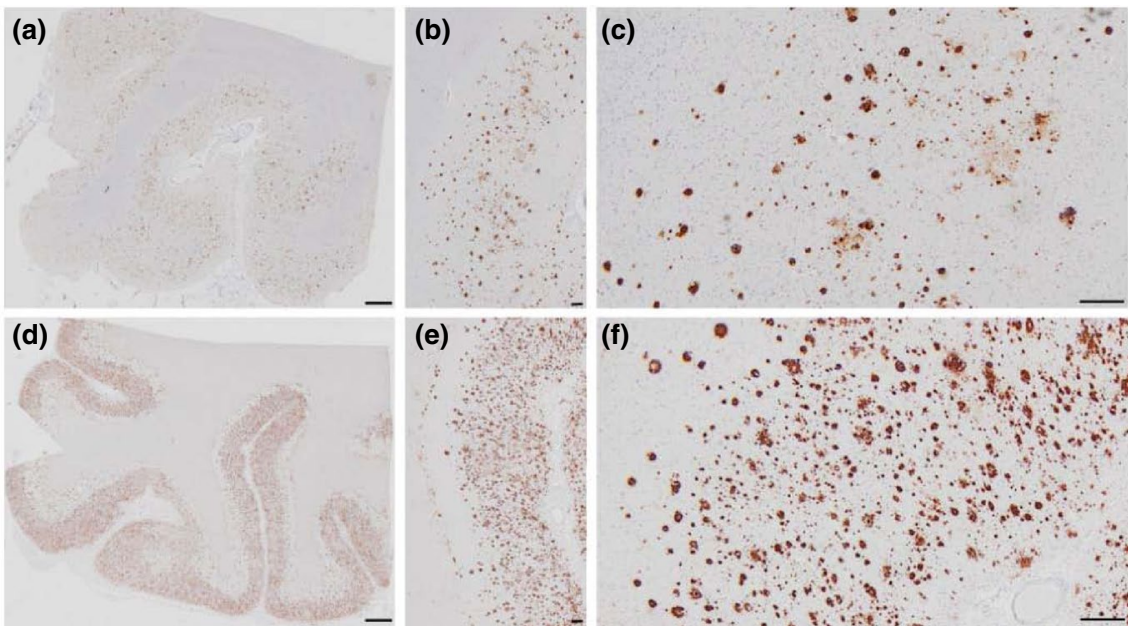

(f)
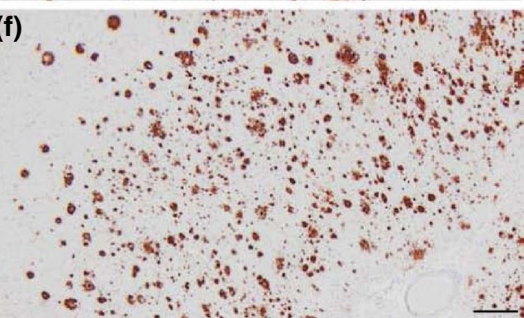

(g)
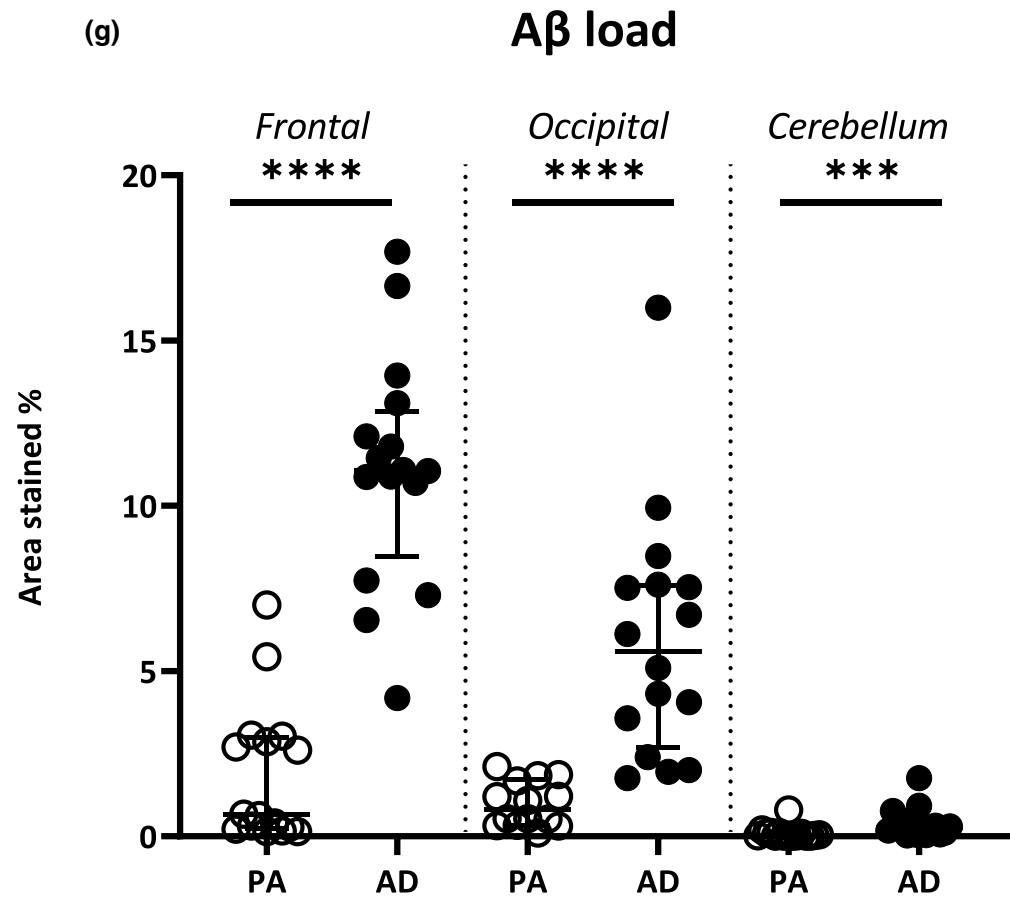

we found an overall trend of lower concentrations of the synapseassociated proteins in AD and FAD compared with PA and controls, indicating synapse dysfunction, impaired synaptic repair processes (RBM3), and possible synaptic loss in AD and FAD but not in PA These results are in line with the hypothesis that the PA patients are cognitively unimpaired since they have not experienced substantial synapse loss, even with the presence of amyloid plaques and neurofibrillary tangles. Our results are also in line with neurogranin results from an AD study from 2018 by Kvartsberg et al., which found no difference between PA and controls but lower neurogranin levels in FAD and AD (Kvartsberg et al., 2019). Additionally, $\alpha$-synuclein and synaptophysin have similarly, with western blot, been shown to have a trend of lower protein levels in AD compared with PA and controls (Wang et al., 2005).

To substantiate these results, a second, larger cohort was analyzed. The validation cohort included only PA and $A D$, but comprised brain tissue from three different brain regions. The results for the synapse-associated biomarkers in the validation study confirmed the key results from the explorative cohort, i.e., decreased levels of synaptic proteins were found in AD brains compared with PA. This was particularly accentuated in the occipital lobe, which seems to have the highest synaptic protein loss, but a similar pattern was also found in the frontal lobe. Cerebellum on the other hand did not seem to be affected to the same extent. These findings are also in line with the current knowledge on the temporal order in which the brain regions are affected in AD (Mattsson et al., 2019). Further, the correlations show that synaptophysin, RBM3, and SNAP-25B seem to be closely associated, but the concentrations of the two synaptotagmins and SNAP-25 (the non-isoform-specific, N-terminal SNAP-25 peptide) often correlated to a substantially lesser degree. Interestingly, the two SNAP-25 peptides quantified thus showed a difference in the results. We have earlier identified several truncated forms of soluble SNAP-25, all N-terminally modified by methionine excision and acetylation. It could therefore be speculated that the differences 

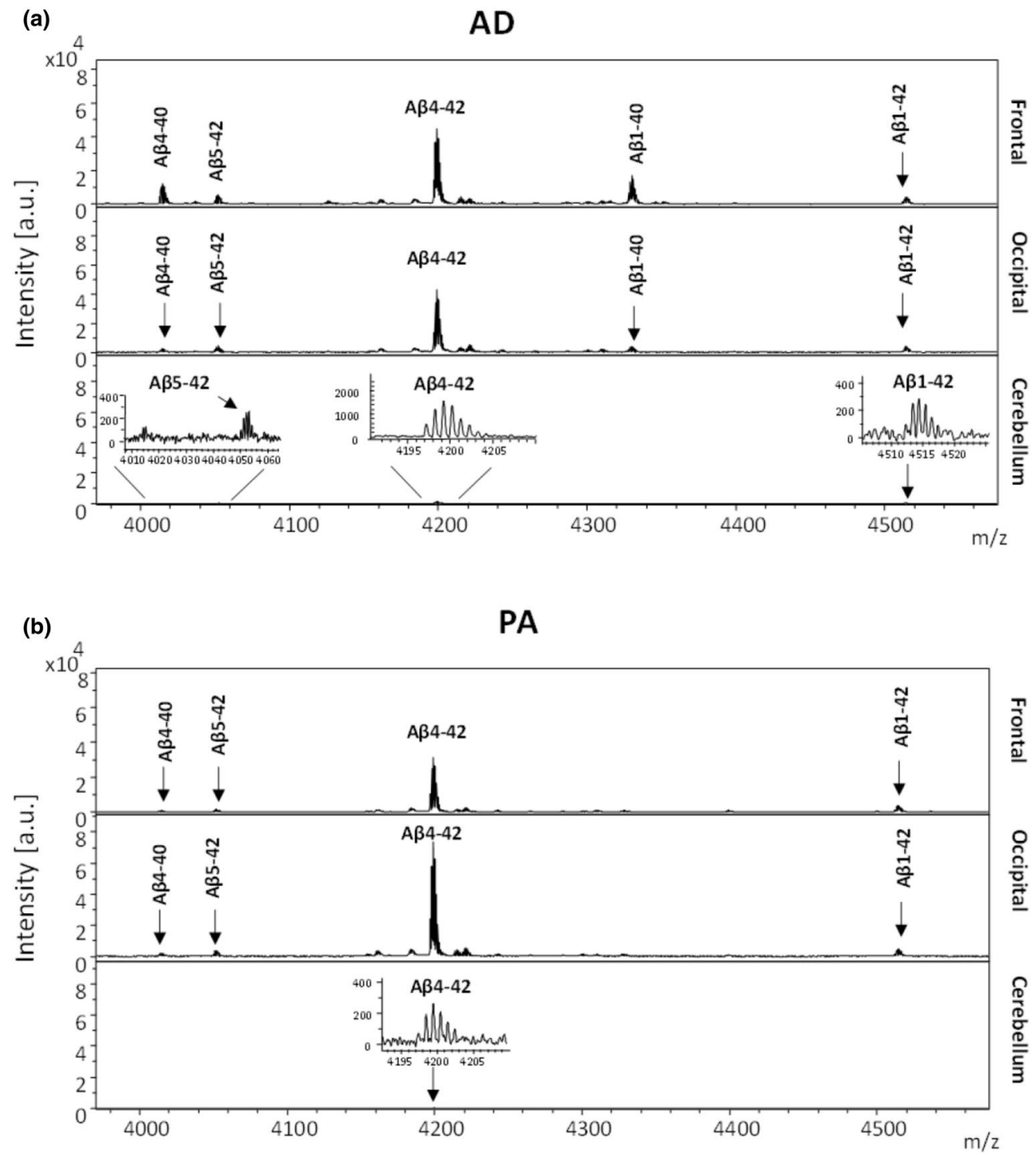

FIGURE 4 Representative MALDI mass spectra of A $\beta$ peptides for an AD (a) and a PA patient (b) for frontal lobe, occipital lobe, and cerebellum, respectively

between the two SNAP-25 forms could be attributed to regional or isoform specific expression or processing pathways (see Figure S3). Further, in several studies, SNAP-25 and synaptotagmin-1 have been shown earlier to have significantly increased CSF levels in AD compared with controls (Brinkmalm, Brinkmalm, Honer, Frölich, et al., 2014; Ohrfelt et al., 2016). There was an association between Braak stage and lower levels of synaptic proteins measured (Figure S10), but the very limited variation in Braak stage (V-VI) for the AD group precluded statistical analysis. In general, given the small size of the cohort, all correlations should be interpreted with caution.

In the validation study, the $A \beta$ load and peptide pattern were investigated in the same tissue samples as the synapse-associated proteins to explore any potential difference between the patient groups. Quantification of $A \beta$ peptides and synapse-associated proteins in the exact same brain tissue samples gave us a unique opportunity to directly compare amyloid load with and without synaptic loss. In the present analysis, we could not only measure differences in overall abundance between $A D$ and PA (with both immunostaining and LC-MS) (Figure 3), but also it was possible to clearly demonstrate a distinct difference in the $A \beta$ peptide pattern between the two groups (Figure 5 and Figure S8). In PA patients, we observed higher relative fractions of $A \beta X-42$ peptides compared with $A D$, while in $A D$ the relative fractions of $A \beta X-40$ peptides were higher compared with PA. Note again that since this a relative fraction measurement, the result should not be interpreted as there was a decrease of $A \beta X-42$ species in $A D$ compared with $P A$, but rather that $A \beta X-40$ was increased substantially more than $A \beta X-42$ in $A D$. As mentioned above, in the LC-ESI-MS data we observe a general increase of all $A \beta$ species in $A D$ vs $P A$ (the LC separation prior to ESI-MS ensures that there is a comparatively small quenching effect compared with the MALDI measurement, where no such separation was performed); a significant increase in the $A \beta$ load in AD compared with PA as determined by immunohistochemistry. 
AD: Frontal

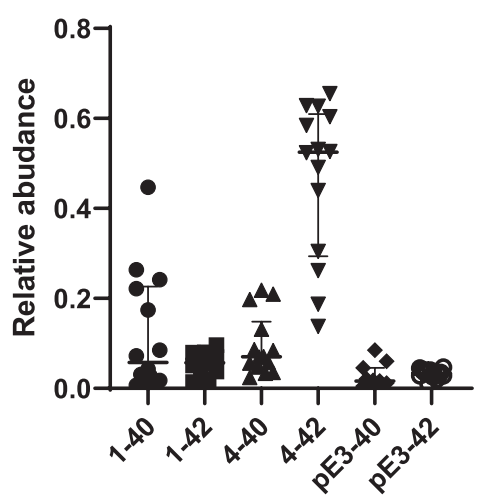

PA: Frontal



AD: Occipital

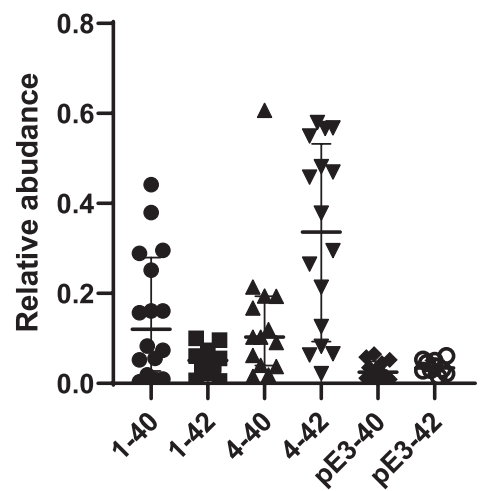

PA: Occipital

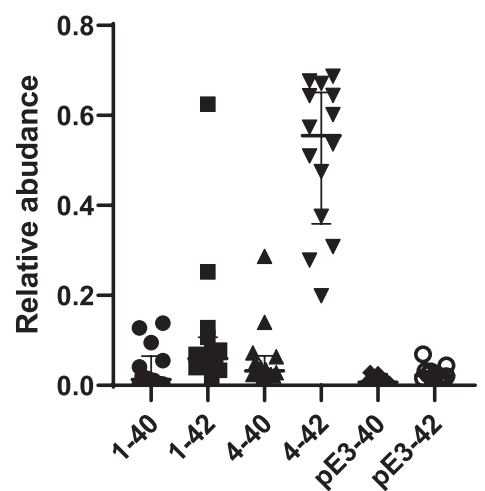

AD: Cerebellum

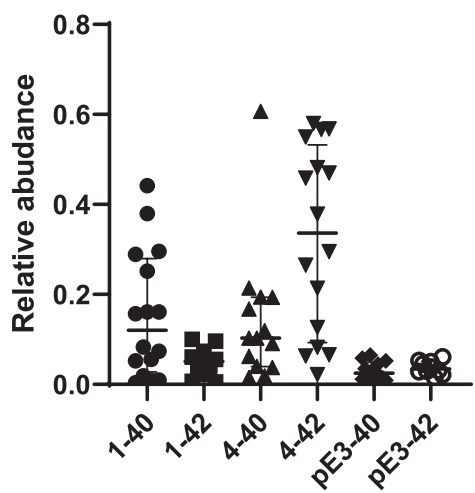

PA: Cerebellum

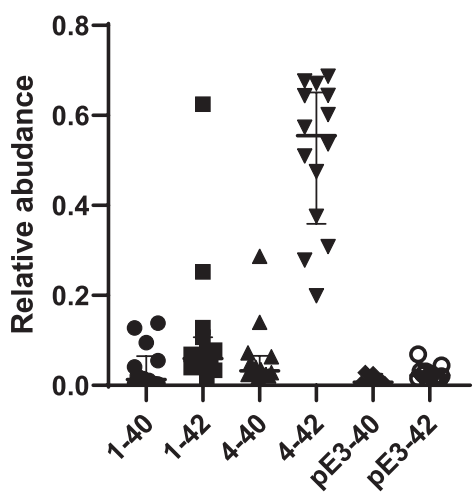

FIGURE 5 Scatter plots showing the relative fraction of the major A $\beta$ peptides in frontal, occipital, and cerebellum in AD ( $n=16$ ) PA $(n=16)$. Higher relative fractions of $A \beta X-40$ are observed in $A D$ compared with $P A$, while increased relative fraction of $A \beta X-42$ is observed in PA compared with AD. $n=$ number of patients

In $A D$, both diffuse and dense-core plaques are present, while in PA the amyloid plaques are mostly diffuse (Iwatsubo et al., 1994b; Michno et al., 2019). Furthermore, the relative abundancies of the pyroglutamate-modified peptides (pGlu A $33-40$ and pGlu $A \beta 3-42$ ) were increased in $A D$ compared with PA. Previous studies have identified $A \beta X-40$ as the major component of the core of an amyloid plaque, while $A \beta X-42$ is localized in diffuse amyloid aggregates (Iwatsubo et al., 1994b; Michno et al., 2019; Mori et al., 1992; Näslund et al., 1994). Pyroglutamate-modified peptides are responsible for cell toxicity (Sofola-Adesakin et al., 2016; Tekirian et al., 1999), a fact that can justify the negative correlation between relative fractions of pGlu $A \beta 3-40$ and pGlu $A \beta 3-42$, and synaptic proteins in AD. Michno et al., have recently proposed that pyroglutamation together with A $\beta 1-40$ deposition are critical events in initiating the formation and maturation of diffuse plaques into dense-cored plaques, with increased neurotoxicity and eventual development into AD (Michno et al., 2019). Rijal Upadhaya et al. have described biochemical stages of a pathological progress of $A \beta$ from non-AD (no $A \beta$ ), via preclinical $A D$ where total $A \beta$ first appears, followed by pGlu $A \beta$, to symptomatic $A D$, where $A \beta$ also may be phosphorylated (Rijal Upadhaya et al., 2014). Although we have not found evidence of phosphorylated $A \beta$ and our study is cross-sectional, our findings in general agree with this chain of events. Our measurements were on a macroscopic level and a combination of diffuse and dense-cored plaques, as well as CAA pathology, was observed, giving us an average representation of the disease pathologies instead of distinct morphological entities. CAA is characterized by the deposition of $A \beta 1-40$ and $A \beta 4-40$ in the vessel walls (Attems et al., 2011; Michno et al., 2019). It can be argued that the AD patients have higher CAA pathology compared with PA, explaining the higher abundance of $A \beta 1-40$. CAA is present in $80 \%$ of $A D$ cases, making it difficult to find patients with no CAA contribution in the $A \beta$ pathology. Since both dense-cored plaques and vessels have $A \beta X-40$ as dominant species, and both are increased in $A D$ vs PA it is difficult to determine the source of the $A \beta X-40$ with the present methodology. To do that the different features have to be analyzed individually, for example with immunohistochemistry or imaging MS. Moreover, A $\beta 1-37,38,39$, which have been previously associated with CAA (Brinkmalm et al., 2019; Gkanatsiou et al., 2019) were detected in some of the CAA individuals. These peptides are not observed to be abundant in the densecore plaques, but are present in vessel wall deposits [Michno 2021 
to be published in the same issue]. This potential link to CAA has to be further investigated.

It would be very valuable to be able to more directly link the plaque development to cognitive decline. However, detailed biochemical analysis can only be performed on post-mortem material, which does not allow for longitudinal studies. Moreover, analysis of $A \beta$ in CSF does not provide sufficient information about $A \beta$ peptide variants in brain. Presently, the only way to conduct longitudinal studies in brain is by PET. Unfortunately, with the PET ligands currently available, it is not possible to obtain detailed $A \beta$ peptide variant information. The PET ligands supposedly bind to fibrillar $A \beta$ and therefore the diffuse plaques would escape detection, although this may be a simplification (Ikonomovic et al., 2020). However, since positive PET signatures may be observed in individuals who show no clinical symptoms (Pike et al., 2011), there is a strong indication that dense-cored plaques are present at an early stage of AD development. Recently, an approach using antibody-based PET ligand has been reported (Fang et al., 2019; Sehlin et al., 2019). This is a promising tool for assessing the diversity of brain $A \beta$ in living individuals, allowing for longitudinal studies.

When investigating the correlations between different $A \beta$ peptides and synapse-associated protein concentrations for the three brain regions we observed that in $A D$ patients the synapseassociated proteins positively correlated with the relative amounts of $A \beta X-42$ in both frontal and occipital brain regions, where $A \beta 4-42$ and $A \beta 5-42$ had the strongest correlation. This positive correlation is an effect of a higher relative fraction of $A \beta X-42$ vs $A \beta X-40$ in individuals cognitively unaffected at the time of death. Contrary to this a negative correlation was observed for relative $A \beta X-40$, with the exception of $A \beta 2-40$, indicating that these $A \beta$ peptides may be involved in the process leading to loss of synaptic function. In other words, there seems to be a clear correlation between the increased relative fractions of $A \beta 1-40, A \beta 4-40$, and pGlu $A \beta 3-40$ and the decreased synaptic protein concentrations, indicating that the formation of the dense-cored plaques might drive the toxic pathology and symptoms present in AD.

Limitations of the study are the small cohorts, and that the quantification was conducted without peptide calibrator standards. An additional problem when analyzing brain is the inability to obtain precisely matching pieces for different individuals. The results should therefore be considered as descriptive. Nevertheless, the results were replicated across brain regions and showed consistent patterns, pinpointing differences in amyloid and synaptic pathology markers between PA and AD that should be of interest to explore in follow-on neuropathological and fluid-based biomarker studies.

\section{5 | CONCLUSIONS}

In conclusion, no or limited synaptic protein loss was found in post-mortem brain tissue from cognitively unimpaired PA patients. However, lower abundancies of synapse-associated proteins were found in brain tissue from AD patients, which signals increased synaptic loss. Furthermore, the $A \beta$ load was significantly higher in $A D$ compared with $\mathrm{PA}$, and $\mathrm{A} \beta$ peptide pattern differences were also identified with the relative abundance of $A \beta X-40$ being higher in $A D$ patients, while for $A \beta X-42$ it was higher in PA patients. Frontal and occipital lobe abundancies of the synaptic biomarkers correlated positively with the relative concentration of $A \beta X-42$ peptides and negatively with the relative concentration of $A \beta X-40$ peptides. From these results, it is possible to conclude that although PA patients have amyloid pathology, the synaptic function appears to be preserved supporting that PA is not prodromal AD. The age of the PA individuals at time of death was high, which might indicate a slow progression possibly due to some protective factor. Alternatively, it may be tempting to suggest that PA is the preclinical stage of AD. However, from this study we can neither confirm nor disprove such statements. To do this, longitudinal in situ studies would be required, but currently there are no scanning techniques available that can provide the required level of detail. Further brain studies along with longitudinal studies of synaptic CSF or imaging biomarkers would be very valuable in elucidating these pathological processes.

\section{DECLARATION OF INTERESTS}

H.Z. has served at scientific advisory boards for Wave, Samumed, CogRx and Roche Diagnostics and has given open lectures for Alzecure. KB has served as a consultant or at advisory boards for Axon, Biogen, CogRx, Lilly, MagQu, Novartis and Roche Diagnostics. $\mathrm{HZ}$ and $\mathrm{KB}$ are co-founders of Brain Biomarker Solutions in Gothenburg AB, a GU Ventures-based platform company at the University of Gothenburg. The other authors declare no competing interest.

\section{ACKNOWLEDGMENTS}

The study was supported by grants from the Swedish Research Council, the European Research Council, Alzheimerfonden, Stiftelsen för Gamla Tjänarinnor, the Knut and Alice Wallenberg Foundation, the Torsten Söderberg Foundation, Swedish State Support for Clinical Research, and Demensfonden. TL is supported by an Alzheimer's Research UK senior fellowship. The Queen Square Brain Bank is supported by the Reta Lila Weston Institute of Neurological Studies, UCL Institute of Neurology. HZ is a Wallenberg Scholar.

\section{AUTHOR CONTRIBUTIONS}

EG, JN, CT, AB, EP, HZ, KB, TL, GB, drafted the study design. CT and TL performed the neuropathological assessment and sample collection. EG, JN, AV, and HK performed the protein extraction of human post-mortem tissue. EG and JN carried out sample processing, MS data collection, analysis and interpretation. AB, EP, and GB assisted with MS data analysis and interpretation. All authors participated in writing the manuscript.

\section{DATA AVAILABILITY STATEMENT}

The data are available from the authors upon request. 


\section{ORCID}

Eleni Gkanatsiou (D) https://orcid.org/0000-0003-4443-2836

Henrik Zetterberg (D) https://orcid.org/0000-0003-3930-4354

\section{REFERENCES}

Attems,J.,Jellinger, K.,Thal, D. R., \&Van Nostrand,W.(2011). Review: sporadic cerebral amyloid angiopathy. Neuropathology and Applied Neurobiology, 37, 75-93. https://doi.org/10.1111/j.1365-2990.2010.01137.x.

Bankhead, P., Loughrey, M. B., Fernández, J. A., Dombrowski, Y., McArt, D. G., Dunne, P. D., McQuaid, S., Gray, R. T., Murray, L. J., Coleman, H. G., James, J. A., Salto-Tellez, M., \& Hamilton, P. W. (2017). QuPath: Open source software for digital pathology image analysis. Scientific Reports, 7, 16878. https://doi.org/10.1038/s41598-017-17204-5.

Barthet, G., Jorda-Siquier, T., Rumi-Masante, J., Bernadou, F., Mueller, U., \& Mulle, C. (2018). Presenilin-mediated cleavage of APP regulates synaptotagmin-7 and presynaptic plasticity. Nature Communications, 9, 4780. https://doi.org/10.1038/s41467-018-06813-x.

Braak, H., \& Braak, E. (1991). Neuropathological stageing of Alzheimerrelated changes. Acta Neuropathologica, 82, 239-259. https://doi. org/10.1007/BF00308809.

Brinkmalm, A., Brinkmalm, G., Honer, W. G., Frölich, L., Hausner, L., Minthon, L., Hansson, O., Wallin, A., Zetterberg, H., Blennow, K., \& Öhrfelt, A. (2014). SNAP-25 is a promising novel cerebrospinal fluid biomarker for synapse degeneration in Alzheimer's disease. Molecular Neurodegeneration, 9, 53. https://doi. org/10.1186/1750-1326-9-53.

Brinkmalm, A., Brinkmalm, G., Honer, W. G., Moreno, J. A., Jakobsson, J., Mallucci, G. R., Zetterberg, H., Blennow, K., \& Ohrfelt, A. (2014b). Targeting synaptic pathology with a novel affinity mass spectrometry approach. Molecular \& Cellular Proteomics: MCP, 13, 2584-2592. https://doi.org/10.1074/mcp.M114.040113.

Brinkmalm, A., Brinkmalm, G., Honer, W. G., Moreno, J. A., Jakobsson, J., Mallucci, G. R., Zetterberg, H., Blennow, K., \& Öhrfelt, A. (2014c). Targeting synaptic pathology with a novel affinity mass spectrometry approach. Molecular \& Cellular Proteomics, 13, 2584-2592. https://doi.org/10.1074/mcp.M114.040113.

Brinkmalm, G., Hong, W., Wang, Z., Liu, W., O'Malley, T., Sun, X., Frosch, M., Selkoe, D., Portelius, E., Zetterberg, H., Blennow, K., \& Walsh, D. (2019). Identification of neurotoxic cross-linked amyloid- $\beta$ dimers in the Alzheimer's brain. Brain, 142(5), 1441-1457. http://doi. org/10.1093/brain/awz066

Brinkmalm, G., Portelius, E., Öhrfelt, A., Mattsson, N., Persson, R., Gustavsson, M., Vite, C., Gobom, J., Månsson, J.E., Nilsson, J., Halim, A., Larson, G., Rüetschi, U., Zetterberg, H., Blennow, K., \& Brinkmalm, A. (2012). An online nano-LC-ESI-FTICR-MS method for comprehensive characterization of endogenous fragments from amyloid $\beta$ and amyloid precursor protein in human and cat cerebrospinal fluid. Journal of Mass Spectrometry, 47(5), 591-603. http:// doi.org/10.1002/jms.2987

Chen, Y., Fu, A. K. Y., \& Ip, N. Y. (2019). Synaptic dysfunction in Alzheimer's disease: Mechanisms and therapeutic strategies. Pharmacology \& Therapeutics, 195, 186-198. https://doi.org/10.1016/j.pharm thera.2018.11.006.

Clarke, M. T. M., Brinkmalm, A., Foiani, M. S., Woollacott, I. O. C., Heller, C., Heslegrave, A., Keshavan, A., Fox, N. C., Schott, J. M., Warren, J. D., Blennow, K., Zetterberg, H., \& Rohrer, J. D. (2019). CSF synaptic protein concentrations are raised in those with atypical Alzheimer's disease but not frontotemporal dementia. Alzheimer's Research \& Therapy, 11, 105. https://doi.org/10.1186/s13195-019-0564-2.

Cline, E. N., Bicca, M. A., Viola, K. L., \& Klein, W. L. (2018). The amyloidbeta oligomer hypothesis: Beginning of the third decade. Journal of Alzheimer's Disease, 64, S567-S610.

Courtney, N. A., Bao, H., Briguglio, J. S., \& Chapman, E. R. (2019). Synaptotagmin 1 clamps synaptic vesicle fusion in mammalian neurons independent of complexin. Nature Communications, 10, 4076. https://doi.org/10.1038/s41467-019-12015-w.

Davidsson, P., \& Blennow, K. (1998). Neurochemical dissection of synaptic pathology in Alzheimer's disease. International Psychogeriatrics, 10, 11-23. https://doi.org/10.1017/S1041610298005110.

DeKosky, S. T., Ikonomovic, M. D., Styren, S. D., Beckett, L., Wisniewski, S., Bennett, D. A., Cochran, E. J., Kordower, J. H., \& Mufson, E. J. (2002). Upregulation of choline acetyltransferase activity in hippocampus and frontal cortex of elderly subjects with mild cognitive impairment. Annals of Neurology: Official Journal of the American Neurological Association and the Child Neurology Society, 51, 145155. https://doi.org/10.1002/ana.10069.

Fang, X. T., Hultqvist, G., Meier, S. R., Antoni, G., Sehlin, D., \& Syvanen, S. (2019). High detection sensitivity with antibody-based PET radioligand for amyloid beta in brain. Neurolmage, 184, 881-888. https:// doi.org/10.1016/j.neuroimage.2018.10.011.

Galasko, D., Xiao, M., Xu, D., Smirnov, D., Salmon, D. P., Dewit, N., Vanbrabant, J., Jacobs, D., Vanderstichele, H., Vanmechelen, E., \& Worley, P. (2019). Synaptic biomarkers in CSF aid in diagnosis, correlate with cognition and predict progression in $\mathrm{MCl}$ and Alzheimer's disease. Alzheimers Dement (N Y), 5, 871-882. https:// doi.org/10.1016/j.trci.2019.11.002.

Gkanatsiou, E., Portelius, E., Toomey, C. E., Blennow, K., Zetterberg, H., Lashley, T., \& Brinkmalm, G. (2019). A distinct brain beta amyloid signature in cerebral amyloid angiopathy compared to Alzheimer's disease. Neuroscience Letters, 701, 125-131. https:// doi.org/10.1016/j.neulet.2019.02.033.

Hardy, J. A., \& Higgins, G. A. (1992). Alzheimer's disease: The amyloid cascade hypothesis. Science, 256, 184-185. https://doi.org/10.1126/ science.1566067.

Hyman, B. T., Phelps, C. H., Beach, T. G., Bigio, E. H., Cairns, N. J., Carrillo, M. C., Dickson, D. W., Duyckaerts, C., Frosch, M. P., Masliah, E., Mirra, S. S., Nelson, P. T., Schneider, J. A., Thal, D. R., Thies, B., Trojanowski, J. Q., Vinters, H. V., \& Montine, T. J. (2012). National institute on Aging-Alzheimer's association guidelines for the neuropathologic assessment of Alzheimer's disease. Alzheimer's \& Dementia: the Journal of the Alzheimer's Association, 8, 1-13. https:// doi.org/10.1016/j.jalz.2011.10.007.

Ikonomovic, M. D., Buckley, C. J., Abrahamson, E. E., Kofler, J. K., Mathis, C. A., Klunk, W. E., \& Farrar, G. (2020). Post-mortem analyses of $\mathrm{PiB}$ and flutemetamol in diffuse and cored amyloid-beta plaques in Alzheimer's disease. Acta Neuropathologica, 140, 463-476.

Irfan, M., Gopaul, K. R., Miry, O., Hökfelt, T., Stanton, P. K., \& Bark, C. (2019). SNAP-25 isoforms differentially regulate synaptic transmission and long-term synaptic plasticity at central synapses. Scientific Reports, 9, 1-14. https://doi.org/10.1038/s41598-019-42833-3.

Iwatsubo, T., Mann, D. M., Odaka, A., Suzuki, N., \& Ihara, Y. (1995). Amyloid beta protein (A beta) deposition: A beta 42(43) precedes A beta 40 in Down syndrome. Annals of Neurology, 37, 294-299.

Iwatsubo, T., Odaka, A., Suzuki, N., Mizusawa, H., Nukina, N., \& Ihara, Y. (1994a). Visualization of $A$ beta $42(43)$ and $A$ beta 40 in senile plaques with end-specific $A$ beta monoclonals: Evidence that an initially deposited species is A beta 42(43). Neuron, 13, 45-53.

Iwatsubo, T., Odaka, A., Suzuki, N., Mizusawa, H., Nukina, N., \& Ihara, Y. (1994b). Visualization of $A \beta 42$ (43) and $A \beta 40$ in senile plaques with end-specific $A \beta$ monoclonals: Evidence that an initially deposited species is A $\beta 42$ (43). Neuron, 13, 45-53. https://doi. org/10.1016/0896-6273(94)90458-8.

Jack, C. R., Knopman, D. S., Jagust, W. J., Petersen, R. C., Weiner, M. W., Aisen, P. S., Shaw, L. M., Vemuri, P., Wiste, H. J., Weigand, S. D., Lesnick, T. G., Pankratz, V. S., Donohue, M. C., \& Trojanowski, J. Q. (2013a). Tracking pathophysiological processes in Alzheimer's disease: An updated hypothetical model of dynamic biomarkers. The Lancet Neurology, 12, 207-216. https://doi.org/10.1016/S1474 $-4422(12) 70291-0$. 
Jack, C. R., Knopman, D. S., Jagust, W. J., Petersen, R. C., Weiner, M. W., Aisen, P. S., Shaw, L. M., Vemuri, P., Wiste, H. J., Weigand, S. D., Lesnick, T. G., Pankratz, V. S., Donohue, M. C., \& Trojanowski, J. Q. (2013b). Tracking pathophysiological processes in Alzheimer's disease: An updated hypothetical model of dynamic biomarkers. The Lancet Neurology, 12, 207-216. https://doi.org/10.1016/S1474 -4422(12)70291-0.

Kvartsberg, H., Lashley, T., Murray, C. E., Brinkmalm, G., Cullen, N. C., Hoglund, K., Zetterberg, H., Blennow, K., \& Portelius, E. (2019). The intact postsynaptic protein neurogranin is reduced in brain tissue from patients with familial and sporadic Alzheimer's disease. Acta Neuropathologica, 137, 89-102. https://doi.org/10.1007/s0040 1-018-1910-3.

Mattsson, N., Palmqvist, S., Stomrud, E., Vogel, J., \& Hansson, O. (2019). Staging beta-amyloid pathology with amyloid positron emission tomography. JAMA Neurology, 76(11), 1319-1329. https://doi. org/10.1001/jamaneurol.2019.2214

McKhann, G., Drachman, D., Folstein, M., Katzman, R., Price, D., \& Stadlan, E. M. (1984). Clinical diagnosis of Alzheimer's disease: Report of the NINCDS-ADRDA Work Group under the auspices of department of health and human services task force on Alzheimer's disease. Neurology, 34, 939-944. https://doi.org/10.1212/WNL.34.7.939.

Medina, N., Huth-Fehre, T., Westman, A., \& Sundqvist, B. (1994). Matrixassisted laser desorption: Dependence of the threshold fluence on analyte concentration. Organic Mass Spectrometry, 29, 207-209. https://doi.org/10.1002/oms.1210290410.

Michno, W., Nyström, S., Wehrli, P., Lashley, T., Brinkmalm, G., Guerard, L., Syvänen, S., Sehlin, D., Kaya I., Brinet, D., Nilsson, K. P. R., Hammarström, P., Blennow, K., Zetterberg, H., \& Hanrieder, J. (2019). Pyroglutamation of amyloid- $\beta x-42(A \beta x-42)$ followed by A $\beta 1-40$ deposition underlies plaque polymorphism in progressing Alzheimer's disease pathology. Journal of Biological Chemistry, 294(17), 6719-6732. http://doi.org/10.1074/jbc.ra118.006604

Mohrmann, R., de Wit, H., Connell, E., Pinheiro, P. S., Leese, C., Bruns, D., Davletov, B., Verhage, M., \& Sørensen, J. B. (2013). Synaptotagmin interaction with SNAP-25 governs vesicle docking, priming, and fusion triggering. Journal of Neuroscience, 33, 14417-14430. https:// doi.org/10.1523/JNEUROSCI.1236-13.2013.

Montine, T. J., Phelps, C. H., Beach, T. G., Bigio, E. H., Cairns, N. J., Dickson, D. W., Duyckaerts, C., Frosch, M. P., Masliah, E., Mirra, S. S., Nelson, P. T., Schneider, J. A., Thal, D. R., Trojanowski, J. Q., Vinters, H. V., \& Hyman, B. T. (2012). National institute on aging-Alzheimer's association guidelines for the neuropathologic assessment of Alzheimer's disease: A practical approach. Acta Neuropathologica, 123, 1-11. https://doi.org/10.1007/s00401-011-0910-3.

Mori, H., Takio, K., Ogawara, M., \& Selkoe, D. (1992). Mass spectrometry of purified amyloid beta protein in Alzheimer's disease. Journal of Biological Chemistry, 267, 17082-17086. https://doi.org/10.1016/ S0021-9258(18)41896-0.

Mucke, L., \& Selkoe, D. J. (2012). Neurotoxicity of amyloid beta-protein: Synaptic and network dysfunction. Cold Spring Harbor Perspectives in Medicine, 2, a006338.

Naslund, J., Schierhorn, A., Hellman, U., Lannfelt, L., Roses, A. D., Tjernberg, L. O., Silberring, J., Gandy, S. E., Winblad, B., \& Greengard, P. (1994). Relative abundance of Alzheimer A beta amyloid peptide variants in Alzheimer disease and normal aging. Proceedings of the National Academy of Sciences, 91, 8378-8382. https://doi.org/10.1073/pnas.91.18.8378.

Öhrfelt, A., Brinkmalm, A., Dumurgier, J., Brinkmalm, G., Hansson, O., Zetterberg, H., Bouaziz-Amar, E., Hugon, J., Paquet, C., \& Blennow, K. (2016). The pre-synaptic vesicle protein synaptotagmin is a novel biomarker for Alzheimer's disease. Alzheimer's Research \& Therapy, 8, 41. https://doi.org/10.1186/s13195-016-0208-8.

Öhrfelt, A., Zetterberg, H., Andersson, K., Persson, R., Secic, D., Brinkmalm, G., Wallin, A., Mulugeta, E., Francis, P., Vanmechelen, E., Aarsland, D., Ballard, C., Blennow, K., \& Westman-Brinkmalm,
A. (2011). Identification of novel $\alpha$-Synuclein isoforms in human brain tissue by using an online nanoLC-ESI-FTICR-MS method. Neurochemical Research, 36(11), 2029-2042. http://doi. org/10.1007/s11064-011-0527-x

Overk, C. R., \& Masliah, E. (2014). Pathogenesis of synaptic degeneration in Alzheimer's disease and Lewy body disease. Biochemical Pharmacology, 88, 508-516. https://doi.org/10.1016/j. bcp.2014.01.015.

Patterson, C. (2018). World Alzheimer report 2018: the state of the art of dementia research: new frontiers. Alzheimer's Disease International (ADI): London, UK.

Peretti, D., Bastide, A., Radford, H., Verity, N., Molloy, C., Martin, M. G., Moreno, J. A., Steinert, J. R., Smith, T., Dinsdale, D., Willis, A. E., \& Mallucci, G. R. (2015). RBM3 mediates structural plasticity and protective effects of cooling in neurodegeneration. Nature, 518, 236. https://doi.org/10.1038/nature14142.

Pike, K. E., Ellis, K. A., Villemagne, V. L., Good, N., Chételat, G., Ames, D., Szoeke, C., Laws, S. M., Verdile, G., Martins, R. N., Masters, C. L., \& Rowe, C. C. (2011). Cognition and beta-amyloid in preclinical Alzheimer's disease: Data from the AIBL study. Neuropsychologia, 49, 2384-2390. https://doi.org/10.1016/j.neuropsychologia.2011.04.012.

Portelius, E., Tran, A. J., Andreasson, U., Persson, R., Brinkmalm, G., Zetterberg, H., Blennow, K., \& Westman-Brinkmalm, A. (2007). Characterization of amyloid beta peptides in cerebrospinal fluid by an automated immunoprecipitation procedure followed by mass spectrometry. Journal of Proteome Research, 6, 4433-4439.

Reddy, P. H., Mani, G., Park, B. S., Jacques, J., Murdoch, G., Whetsell, W. Jr, Kaye, J., \& Manczak, M. (2005). Differential loss of synaptic proteins in Alzheimer's disease: Implications for synaptic dysfunction. Journal of Alzheimer's Disease, 7, 103-117. https://doi.org/10.3233/ JAD-2005-7203.

Revesz, T., Holton, J. L., Lashley, T., Plant, G., Frangione, B., Rostagno, A., \& Ghiso, J. (2009). Genetics and molecular pathogenesis of sporadic and hereditary cerebral amyloid angiopathies. Acta Neuropathologica, 118, 115-130. https://doi.org/10.1007/s0040 1-009-0501-8.

Rijal Upadhaya, A., Kosterin, I., Kumar, S., von Arnim, C. A., Yamaguchi, H., Fandrich, M., Walter, J., \& Thal, D. R. (2014). Biochemical stages of amyloid-beta peptide aggregation and accumulation in the human brain and their association with symptomatic and pathologically preclinical Alzheimer's disease. Brain, 137, 887-903.

Rossetti, H. C., Munro Cullum, C., Hynan, L. S., \& Lacritz, L. H. (2010). The CERAD neuropsychologic battery total score and the progression of Alzheimer disease. Alzheimer Disease and Associated Disorders, 24, 138-142. https://doi.org/10.1097/WAD.0b013e3181b76415.

Sehlin, D., \& Syvanen, S. (2019). Engineered antibodies: New possibilities for brain PET? European Journal of Nuclear Medicine and Molecular Imaging, 46, 2848-2858. https://doi.org/10.1007/s00259-01904426-0.

Skrobot, O. A., Attems, J., Esiri, M., Hortobágyi, T., Ironside, J. W., Kalaria, R. N., King, A., Lammie, G. A., Mann, D., Neal, J., Ben-Shlomo, Y., Kehoe, P. G., \& Love, S. (2016). Vascular cognitive impairment neuropathology guidelines (VCING): The contribution of cerebrovascular pathology to cognitive impairment. Brain, 139, 2957-2969. https://doi.org/10.1093/brain/aww214.

Sofola-Adesakin, O., Khericha, M., Snoeren, I., Tsuda, L., \& Partridge, L. (2016). pGluAbeta increases accumulation of Abeta in vivo and exacerbates its toxicity. Acta Neuropathologica Communications, 4, 109.

Südhof, T. C. (2004). The synaptic vesicle cycle. Annual Review of Neuroscience, 27, 509-547.

Sugita, S., Shin, O. H., Han, W., Lao, Y., \& Südhof, T. C. (2002). Synaptotagmins form a hierarchy of exocytotic $\mathrm{Ca} 2+$ sensors with distinct Ca2+ affinities. The EMBO Journal, 21, 270-280.

Sze, C.-I., Troncoso, J. C., Kawas, C., Mouton, P., Price, D. L., \& Martin, L. J. (1997). Loss of the presynaptic vesicle protein synaptophysin 
in hippocampus correlates with cognitive decline in Alzheimer disease. Journal of Neuropathology \& Experimental Neurology, 56, 933944. https://doi.org/10.1097/00005072-199708000-00011.

Tamaoka, A., Sawamura, N., Odaka, A., Suzuki, N., Mizusawa, H., Shoji, S., \& Mori, H. (1995). Amyloid beta protein 1-42/43 (A beta 1-42/43) in cerebellar diffuse plaques: Enzyme-linked immunosorbent assay and immunocytochemical study. Brain Research, 679, 151-156.

Tekirian, T. L., Yang, A. Y., Glabe, C., \& Geddes, J. W. (1999). Toxicity of pyroglutaminated amyloid beta-peptides $3(\mathrm{pE})-40$ and -42 is similar to that of A beta1-40 and -42. Journal of Neurochemistry, 73, 1584-1589.

Terry, R. D., Masliah, E., Salmon, D. P., Butters, N., DeTeresa, R., Hill, R., Hansen, L. A., \& Katzman, R. (1991). Physical basis of cognitive alterations in Alzheimer's disease: Synapse loss is the major correlate of cognitive impairment. Annals of Neurology: Official Journal of the American Neurological Association and the Child Neurology Society, 30, 572-580. https://doi.org/10.1002/ana.410300410.

Thal, D. R., Rub, U., Orantes, M., \& Braak, H. (2002). Phases of A betadeposition in the human brain and its relevance for the development of AD. Neurology, 58, 1791-1800.

Tible, M., Sandelius, Å., Höglund, K., Brinkmalm, A., Cognat, E., Dumurgier, J., Hugon, J., Paquet, C., \& Blennow, K. (2020). Dissection of synaptic pathways through the analysis of cerebrospinal fluid biomarkers: A combined tool for predicting Alzheimer's disease. Neurology, 95(8), 953-961.

Wang, D.-S., Lipton, R. B., Katz, M. J., Davies, P., Buschke, H., Kuslansky, G., Verghese, J., Younkin, S. G., Eckman, C., \& Dickson, D. W. (2005). Decreased neprilysin immunoreactivity in Alzheimer disease, but not in pathological aging. Journal of Neuropathology and Experimental Neurology, 64, 378-385. https://doi.org/10.1093/ jnen/64.5.378.

Westman, A., Huth-Fehre, T., Plamen, D., Bielawski, J., Medina, N., Sundqvist, B., \& Karas, M. (1994). Matrix-assisted laser desorption/ ionization: Dependence of the ion yield on the laser beam incidence angle. Rapid Communications in Mass Spectrometry, 8, 388-393. https://doi.org/10.1002/rcm.1290080510.

Yan, Y., \& Wang, C. (2006). Abeta42 is more rigid than Abeta40 at the C terminus: Implications for Abeta aggregation and toxicity. Journal of Molecular Biology, 364, 853-862.

\section{SUPPORTING INFORMATION}

Additional Supporting Information may be found online in the Supporting Information section.

How to cite this article: Gkanatsiou, E., Nilsson, J., Toomey, C. E., Vrillon, A., Kvartsberg, H., Portelius, E., Zetterberg, H., Blennow, K., Brinkmalm, A., Lashley, T., \& Brinkmalm, G. (2021). Amyloid pathology and synaptic loss in pathological aging. Journal of Neurochemistry, 00, 1-15. https://doi. org/10.1111/jnc.15487 